\title{
RESENAS
}

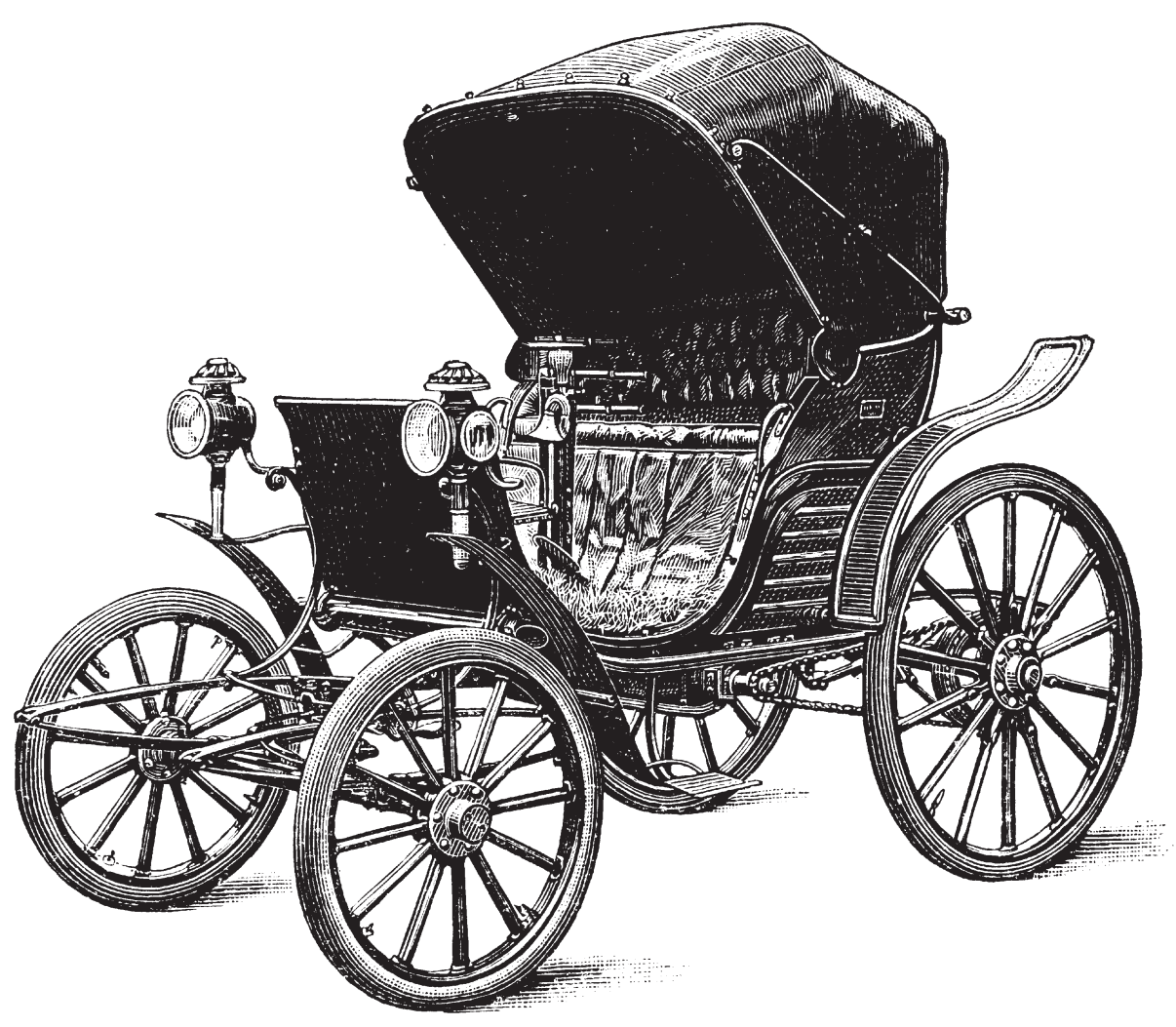





\section{Investigar con corpus en traducción: los retos de un nuevo paradigma}

Gloria Corpas Pastor

Peter Lang, Fráncfort, 2008, 297 págs.

\section{Miriam Seghiri}

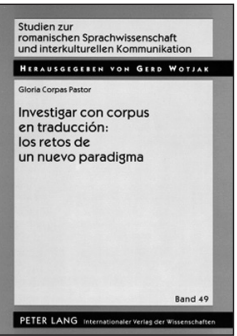

La estructuración y redacción del presente libro, Investigar con corpus en traducción: los retos de un nuevo paradigma, responde a la forma de trabajar a la que nos tiene acostumbrados Gloria Corpas Pastor desde hace años, pues nos encontramos ante una obra clara, minuciosa, progresiva, concisa y exhaustiva. De este modo, el volumen, abierto con un prefacio introductorio en el que la autora nos revela el principal propósito del presente trabajo, «reflexionar en torno al corpus como nuevo paradigma de investigación en Traductología [...] y comprobar hasta qué punto son válidas las hipótesis de simplificación, convergencia y transferencia», se encuentra dividido en cinco grandes capítulos, que se cierran con una meditada conclusión, seguida de las principales obras de consulta manejadas y cinco apéndices.

En los capítulos I, II y in la autora presenta una visión panorámica de las aportaciones que el corpus, hasta la fecha, ha realizado a disciplinas como la Lingüística y la Traductología. De este modo, se inicia la redacción con el capítulo I, «Breve recorrido histórico», en el que se introduce al lector en las políticas europeas en materia de industrias de la lengua, la investigación con corpus en lingüística computacional, desde su vertiente teórica, pasando por los recursos y técnicas, hasta sus aplicaciones. Sigue esta línea el capítulo II, «Metodo- logía de corpus para el establecimiento de la equivalencia», en el que se reflexiona sobre el corpus como un nuevo paradigma, la gramática léxica y sus aplicaciones para la detección $\mathrm{y}$ análisis de equivalentes de forma semi-automática a través de proyectos como Multilingual Corpora, metis o Assist. En el capítulo III, «Aportaciones a los estudios de Traducción e Interpretación», se incide en la contribución del corpus, no sólo desde su vertiente teórica y tecnológica, expresada en los capítulos precedentes, sino para la enseñanza-aprendizaje de la traducción así como de la interpretación. En este punto, se reflexiona en torno a los estudios descriptivos de normas, leyes y universales de la lengua traducida, en concreto, aquellos de simplificación, convergencia y transferencia, que dan paso a los capítulos IV y $\mathrm{v}$ dedicados a los estudios empíricvos de estos tres universales. Así pues, en el capítulo IV «Investigación de la hipótesis de universalidad: organización de los datos», se describen minuciosamente la hipótesis de partida, los objetivos, la composición de la ingente cantidad y calidad de los corpus compilados, la metodología seguida y técnicas empleadas en el diseño experimental, que dan pie al capítulo v, «Investigación de la hipótesis de universalidad: experimentos y resultados», dedicado a la implementación de tales estudios, descripción pormenorizada de los novedosos experimentos realizados, sin parangón hasta la fecha, seguidos del análisis y discusión de los reveladores resultados alcanzados que vienen a poner en entredicho las teorías expuestas hasta el día de hoy, basadas más bien, como indica la propia autora en las Conclusiones (capítulo vi), en la introspección y escasez de datos empíricos a través del análisis manual de corpus de reducido tamaño.

De este modo, quienes se interesan por la Lingüística de Corpus y los Estudios de 
Traducción están de enhorabuena, pues son muchas las aportaciones que realiza la catedrática de Traducción e Interpretación en esta obra. Sirva como botón de muestra la aplicación, por primera vez, de técnicas de Procesamiento de Lenguaje Natural y Lingüística de Corpus para llegar a resultados fiables y aplicables a cualquier lengua, combinación lingüística y género textual con todas las garantías, además de la presentación de una metodología clara y protocolizada para la compilación de corpus cuyo resultado más significativo es, entre otros, El corpus de español peninsular, de enorme utilidad para la investigación y didáctica de la Traducción y de la Interpretación, por sólo citar algunas de sus innumerables futuras aplicaciones. Asimismo, se estudia, en una única obra, tres universales a la vez, arrojando resultados y conclusiones sorprendentes que abrirán nuevas e inexploradas líneas de investigación. Sin duda, esta obra está destinada a marcar un antes y un después.

\section{Traduciendo la prensa}

Marie-Claire Durand y Jean-Marie FLORÈS

Libros Encasa, Málaga, 2008, 206 págs.

María José Hernán dez Guerrero

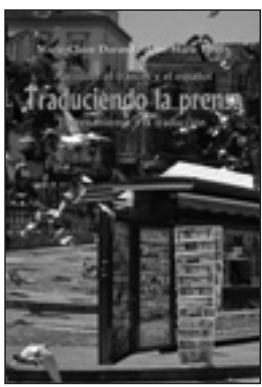

Los manuales de prácticas que se presentan como recopilaciones de textos con sus respectivas propuestas de traducción tienen ya una larga tradición en el ámbito de la enseñanza de las lenguas y de la traducción. Sus autores, profesores de estas materias en su mayoría, los suelen elaborar con fines didácticos, para que los alumnos los utilicen de manera autónoma en el proceso de aprendizaje.

Muchos de estos manuales utilizan textos periodísticos de forma única y exclusiva. $\mathrm{La}$ elección de este tipo textual se fundamenta en su amplia riqueza lingüística y en las posibilidades que ofrece de adentrarse en el empleo actualizado de la lengua. Con todo, presenta un pequeño inconveniente: su carácter efímero, que lo vincula al acontecer diario y le hace quedar rápidamente obsoleto, superado por el devenir de los acontecimientos y los avances que se producen en todos los ámbitos. Pese a ello, las ventajas de su utilización son muchas. Están redactados en una lengua estándar que los hace encajar en diferentes niveles de enseñanza; la variedad de contenidos que presentan permite la selección de aquellos más actuales o atractivos; el lenguaje periodístico, además, es extremadamente rico; la prensa escrita es fiel reflejo de las tendencias de la lengua actual, puerta de entrada y lugar de experimentación lingüística. Sin olvidar que la prensa ofrece una visión completa y actualizada del mundo que nos rodea y que su lectura es uno de los medios más adecuados para conocer la cultura propia y la de otros países.

Estas y otras razones hacen de los textos periodísticos un recurso didáctico habitual, de uso corriente en la elaboración de manuales de prácticas. En lo referente al par de lenguas francés/español (en traducción directa, inversa o ambas a la vez), en los últimos años hemos asistido a la publicación de un buen número de estas obras, que se presentan como una recopilación de textos periodísticos originales con sus correspondientes versiones. Las podemos dividir en dos grandes grupos dependiendo de la finalidad con que se utilice la traducción. En primer lugar, se encuentran aquellas que pretenden incidir en la práctica de la traduc- 
ción profesional. Con un enfoque basado en la experiencia traductora, ofrecen una aportación viva y reflexiva para hacer frente a todas las dificultades — no sólo las lingüísticas - que supone el ejercicio de la traducción. La traducción del texto periodístico, editado por el Grupo Iris en I996 (Alicante: Editorial Club Universitario) constituye un ejemplo de este tipo de manual. Los planteamientos expuestos en su introducción, que encuadran la práctica de la traducción dentro del marco traductológico, y la cuidada traducción de los textos presentados, todos ellos sobradamente anotados con aclaraciones sobre las propuestas de traducción adoptadas, hacen de esta obra una útil herramienta para ahondar de manera autónoma en la práctica de la traducción del francés al español.

En segundo lugar, se encuentran los manuales donde la traducción se utiliza como recurso en la labor de enseñanza-aprendizaje de una lengua extranjera (traducción pedagógica) y que han sido concebidos para alumnos que aprenden el idioma, en este caso el francés o el español, en diferentes titulaciones (Filología, Traducción e Interpretación, Periodismo, etc.). Sin ánimo de ser exhaustivos, entre los más recientes cabe mencionar el Manual de traducción español-francés de textos periodísticos (Granada: Comares, 2007), publicado por Juan Miguel Borda Lapébie - autor igualmente del Manual práctico de traducción español-francés con ejercicios (2003) y Prácticas de traducción español-francés con anotaciones y ejercicios léxico-gramaticales (2004) - Estos manuales van dirigidos a estudiantes de francés que deseen profundizar en el conocimiento de este idioma a través de la práctica de la traducción inversa.

En esta segunda línea se enmarca el manual que reseñamos, Traduciendo la prensa, obra de los profesores Marie-Claire Durand (Departamento de Filología Moderna de la Universidad de las Palmas de Gran Canaria) y Jean-Marie Florès (Departamento de Lenguas Extranjeras Aplicadas de la Universidad de Pau). Va dirigido «a todos los estudiantes de las facultades de Traducción e Interpretación, pero también a los estudiantes de las escuelas de Periodismo, Comercio y Turismo, que estudian español y francés, tanto en España como en Francia, como en todos los países francófonos e hispanófonos». De hecho, los subtítulos con que se presenta este volumen - Aprender el francés y el español. Entrenamiento a la traducción - dicen mucho de su finalidad.

Antes de adentrarnos en su contenido, es necesario que hagamos referencia a un trabajo anterior de estos mismos autores: Traduire la Presse. Entraînement au thème espagnol (París: Ellipses, 2004), pues, como indican en las primeras líneas de su prólogo, han «concebido este manual con el mismo espíritu didáctico que el precedente». De hecho, las semejanzas entre una y otra obra resultan evidentes, pues ambas presentan la misma estructura: un conjunto de temas, cada uno introducido por veinte frases preparatorias y sus versiones, todas sobre un mismo aspecto temático, seguidas de un fragmento de un texto periodístico francés con su propuesta de traducción al español. Al no figurar ningún tipo de introducción metodológica, los lectores se adentran directamente en los distintos temas, de variado contenido. $Y$ ese mismo esquema se repite sucesivamente a lo largo de las veinticinco unidades que componen la obra. $\mathrm{La}$ ausencia de anotaciones, o cualquier otro tipo de comentario, es algo que los autores han buscado expresamente ( L'absence de commentaires est voulue. En effet, notre objectif est d'amener l'étudiant à réfléchir à partir de la traduction proposée», se puede leer en el prólogo del primer volumen); la finalidad, pues, es clara: el alumno debe llegar de manera autónoma a aprehender 
las diferentes etapas del proceso de traducción que han dado lugar a las versiones presentadas.

Como la estructuración de ambas obras es 244 idéntica, el único cambio que se aprecia entre una y otra es la renovación de los textos utilizados: en la segunda se han introducido nuevas frases y fragmentos de textos, tal vez, pensamos, por el carácter efímero de los textos periodísticos al que antes aludíamos, que en el transcurso de pocos años les hace perder actualidad. Traduciendo la prensa presenta una selección textual atractiva, con temas de plena vigencia - como es el caso del cambio climático, la biopiratería, el comercio justo o el Alzheimer-, amena por los variados contenidos y rica en referencias culturales para los alumnos que se adentran en el binomio francés/español.

Hay que señalar, además, que ofrece otra novedad con respecto al primer volumen: la inclusión de un glosario final (español-francés), ideado para que los estudiantes memoricen cierto número de palabras esenciales, extraídas de la prensa, y sirva de base para la creación de un léxico propio conforme avancen en sus estudios lingüísticos. También figuran unas tablas de empleos y giros con los verbos ser y estar, que pueden ser útiles para estudiantes francófonos.

La presentación y el manejo de este manual se habrían visto favorecidos si los autores hubieran cuidado con más detalle algunos aspectos de la edición. Así, por ejemplo, la ausencia de un índice paginado no facilita en absoluto la localización de cualquiera de los temas con los que se quiera trabajar o en los que se quiera consultar algún dato. El lector se ve obligado a rebuscar entre las páginas del libro si quiere localizar un tema en concreto de los que se le ofrecen en la tabla de materias final. Del mismo modo, las versiones al español muestran numerosas interferencias del original francés fácilmente subsanables si se hubiera llevado a cabo una revisión más atenta. Esas interferencias abarcan desde elementos sintácticos (la enfermedad d'Alzheimer, p. 8I) a léxicos (Tchad, p. III), y se extienden a cuestiones de puntuación y de uso de las mayúsculas en español.

Estos detalles, sin embargo, no restan valor a la obra. La amplia experiencia docente de los autores queda patente en la preparación de los distintos temas. $\mathrm{El}$ alumno que quiera avanzar de manera autónoma en la práctica de la traducción del francés al español encontrará aquí una valiosa herramienta, con una amplia muestra de textos actuales, de temática diversa, y con unas propuestas de traducción por lo general muy trabajadas. La distribución de los textos —originales frente a traducciones - permite que las consultas sean cómodas. En resumidas cuentas, desde un planteamiento específico, como es facilitar de entrada la versión española de los originales, los autores proponen al alumnado un recorrido inverso por el proceso de traducción: partir del producto, para acabar construyendo la propia «teoría» y ahondar, así, en la naturaleza de las lenguas y de la traducción.

\section{Recepción y Traducción. Síntesis y crítica de una relación interdisciplinaria María Mercedes Enríquez Aranda Universidad de Málaga, Málaga, 2007, I8I págs.}

Rocio García Jiménez

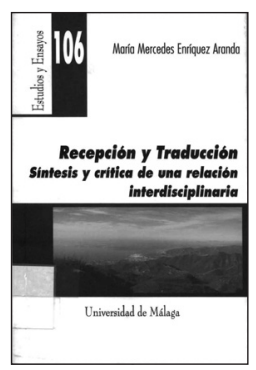
Desde siempre, uno de los elementos que han caracterizado y definido a los estudios sobre la traducción es la unión que éstos establecen con otras disciplinas. Esta vinculación interdisciplinaria constituye en la actualidad un pilar fundamental de 
la traductología. María Mercedes Enríquez Aranda, profesora de la Universidad Pablo de Olavide en Sevilla y autora de la presente obra, no sólo es consciente de la importancia de este hecho, sino que además se alza como defensora de él, lo cual constituye un paso innovador, necesario y útil para la traductología. En el libro, la autora se centra en la estrecha relación entre recepción y traducción y muestra cómo la cooperación entre ambas, junto con otras corrientes, puede dar lugar a una reformulación metodológica en las investigaciones sobre la traducción que, sin duda, hará la disciplina más interesante y real.

Para asentar las bases de su teoría, Enríquez Aranda realiza una excelente labor de recopilación de información sobre la evolución histórica y las corrientes teóricas más destacables de la recepción y de la traducción. La autora parte de la base de que, para que la reformulación metodológica mencionada anteriormente sea posible, es necesario esclarecer qué es la recepción y cuáles son las conexiones que ésta presenta con la actividad traductora y traductológica. El libro comienza, pues, con la consideración de la traducción como forma de recepción de literatura extranjera. A raíz de ello, la investigación se organiza en dos partes principales: cómo los estudios literarios han tratado la recepción y cómo lo han hecho los estudios sobre la traducción. En este punto, el lector se encontrará, en primera instancia, ante un estudiado, exhaustivo y bien organizado recorrido por la evolución de los estudios literarios del siglo xx y la estética de la recepción, junto con las ideas de los más destacados representantes de las principales líneas teóricas. En segundo lugar, está el desarrollo de los estudios sobre la traducción en el siglo xx y la exposición de las teorías de los estudios descriptivos de traducción, donde se mencionan la escuela de la manipulación, la teoría del polisistema y las normas de traducción de Toury y Hermans, principalmente. Esta parte concluye con un análisis sobre el giro cultural en el que se incluyen la idea de traducción como reescritura y la (in)visibilidad del traductor de Venuti. Cabe destacar que este segundo bloque dedicado a los estudios sobre la traducción se trata desde la perspectiva de la traducción literaria.

Una vez que se han delimitado los fundamentos teóricos de la recepción y su evolución desde el punto de vista de la teoría literaria y la traductología, Enríquez Aranda sitúa al lector en el contexto actual de la recepción, la cual muestra su preocupación e interés hacia la cultura y contribuye a ella, al igual que sucede con los estudios sobre la traducción. Esto, unido a la interdisciplinariedad típica de estos últimos, nos hace llegar de nuevo al punto de partida, es decir, a la colaboración que propone la autora entre traducción y recepción para la elaboración de una metodología interdisciplinaria que de una nueva salida fructífera y tangible a los estudios sobre la traducción.

Curiosa y reveladora es la mención de la autora sobre el cambio de orientación que han de seguir los investigadores, quienes deben abogar por una investigación basada en el diálogo y la contribución recíproca entre disciplinas y dejar de trabajar de forma aislada. Ni que decir cabe que Enríquez Aranda predica con el ejemplo, ya que su investigación es precisamente eso, un diálogo entre recepción y traducción y una manera moderna y real de enfocar los estudios sobre la traducción en la que se tienen en cuenta factores tan importantes como, por ejemplo, los culturales.

Sin duda, el presente libro constituye un trabajo de investigación minucioso y bien elaborado y estructurado que presenta la novedad de haber asentado de manera clara 
y concisa los fundamentos teóricos de la recepción en relación con la traducción, y que señala cuál es el camino que seguirán a partir de ahora (y que, de hecho, ya están siguiendo) los estudios sobre la traducción. La visión de Enríquez Aranda sobre éstos es una visión renovada y quizás más compleja que abre muchas puertas (tanto teóricas como prácticas) a la investigación en traducción. De hecho, podría decirse que la obra conforma en sí misma la reformulación metodológica que propone su autora, coherente en todo momento con sus líneas de investigación.

A través de este libro, Enríquez Aranda enseña a ver la traducción de una manera distinta. De hecho, tal y como ella misma apunta, citando a Vidal Claramonte (1998, p. 149), «Esta nueva forma de entender la traducción es, desde luego, más arriesgada, pero también mucho más interesante».

\section{La traducción de la A a la $Z$ \\ Vicente Fernández González (com.) \\ Córdoba, Berenice, 2008, 233 págs.}

Juan Jesús Zaro

Estos últimos meses he disfrutado de la lec-

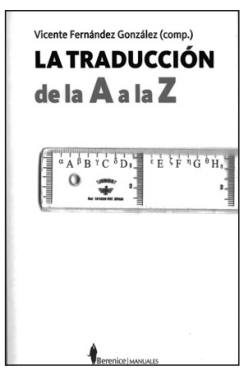
tura de tres libros sobre la Traducción que a la vez me han aportado elementos nuevos o aclarado conceptos hasta ahora difusos. Una combinación que, desafortunadamente, no suele ser muy frecuente. El primero es el de Gregory Rabassa If This Be Treason. Translation and Its Discontents (Nueva York: New Directions Books, 2005), una especie de «memorias» en las que el autor desgrana capítulo a capítulo las dificultades que le depararon, en su labor de traducción al inglés, Goytisolo, García Márquez, Vargas Llosa o Clarice Linspector, entre otros cuarenta autores traducidos. Rabassa, reputado traductor al inglés de literatura contemporánea en español y portugués, se esfuerza por definir de modo retrospectivo las características de los escritores que ha traducido y los pequeños, y enormes, desafíos que a partir de ellas hubo de afrontar en su labor traductora.

El segundo es el de Douglas R. Hofslander Le ton Beau de Marot (Nueva York: Basic Books, 1997), un ensayo furiosamente antiacadémico en el que, a partir de un pretexto muy bien urdido, las diversas propuestas de traducción al inglés de un poema del poeta francés Clément Marot, el autor expone una serie de reflexiones sobre el acto de traducir. Aunque aparentemente inconexas, Hofslander logra hilvanar, de modo sutil, un discurso coherente en el que anécdotas, alusiones e historias diversas ilustran el funcionamiento de su «mente» traductora y sus estrategias para resolver problemas. Y el tercero es la obra que nos ocupa en esta reseña, el libro del profesor Vicente Fernández La traducción de la A a la Z, publicado por Berenice en 2008.

Los tres tienen tres características comunes que merece la pena destacar. Una es su estructura, distinta e innovadora con respecto a la literatura académica que estamos acostumbrados a leer. Otra, la extrema creatividad con que han sido concebidos y realizados para marcar, precisamente, esa llamativa diferencia. Y la última, el haber sido elaborados por expertos y reconocidos traductores, cuya experiencia profesional queda reflejada en ellos en mayor o menor grado.

Pero volvamos a la obra del profesor 
Fernández, cuya presencia en ella (él mismo se define como "compilador») parece, a primera vista, escasa, limitándose a la breve introducción y a las notas a pie de página. El libro, estructurado en forma de glosario, se divide en veintisiete secciones, tituladas según las letras del alfabeto (falta la correspondiente a la $L L$ ) seguidas de una palabra. Así, la primera sección es $A$ de animal (politico) y se compone de seis fragmentos de escritos de autores tan diversos como Emilio Lledó, Chema Cobo, A. Badiou o Pedro Bádenas de la Peña. Los demás autores citados en las siguientes secciones conforman un conjunto diverso: textos de teóricos extranjeros de la traducción (Baker, Nida, Steiner) conviven con otros de semiólogos y lingüistas (Albadalejo, Barthes, Coseriu, Eco, Lotman), filósofos (Benjamin, Marx, Marina, Ortega y Gasset), profesores e investigadores españoles de la traducción (Peña, Marco, Mayoral, Marín), poetas y novelistas (Bolaños, Cortázar, Vázquez Montalbán, Verne, Homero, Cavafis, Machado) y el propio autor, que incluye trece textos suyos publicados con anterioridad. La mayor parte de los títulos de las secciones en que se agrupan incluyen una palabra claramente relacionada con conceptos o términos traductológicos. Así, $I$ de Interpretación, $L$ de Lengua o $V$ de Versiones. Otros, no tanto. Véanse $D$ de Derechos, $E$ de Exterioridad, $M$ de Mitos, $P$ de Perplejidad o $Q$ de Quizá. Y otros, finalmente, no parecen tener absolutamente nada que ver con el mundo de la traducción. Es el caso de $C$ de Cornularias, $J$ de Jarabe (de pato), O de Orfelunio, $S$ de Semiosfera, o $Z$ de Zanco Panco, términos cuya elección sólo se explica al leer alguno de los fragmentos que se incluyen. ¿Es pues este libro una obra fragmenta- da? ¿Un «collage» y no una antología, como asegura el propio autor en la introducción? Sin duda. Lo que no es, de ninguna manera, es una mera compilación. La intervención del autor se muestra decisiva en dos aspectos concretos, además de en la inclusión de los escritos propios ya mencionados: el primero, la selección de los textos, siempre sugerentes, que inevitablemente revelan sus preferencias y posibles fobias (¿lo que no incluye?), y que dicen mucho de su trayectoria intelectual e humana; el segundo, en su ubicación, que consigue establecer un ágil diálogo entre textos y que unos y otros se complementen. Los dos aspectos evidencian una mente inquieta, ecléctica y sumamente original cuya curiosidad intelectual le lleva a buscar las fuentes más diversas, a veces enfrentadas, en busca de respuestas. Respuestas que llegan al lector oblicuamente, a partir de la diversidad de opiniones, reforzando la coherencia de una obra que está mucho más pensada y trabajada que otras que, a primera vista, aparentan todo lo contrario.

Junto con los dos libros citados al comienzo, esta obra podría incluirse perfectamente entre las lecturas obligatorias de una asignatura de grado o postgrado. Entre otras cosas, demuestra con brillantez que no siempre es necesario seguir los trillados surcos de la escritura académica para transmitir el conocimiento. $\mathrm{Y}$, posiblemente, al estar pensada para provocar el debate, daría lugar al diálogo, un elemento de aprendizaje todavía poco presente en nuestras aulas al que deberíamos recurrir con más asiduidad. 


\section{Translation Studies at the Interface of Disciplines}

248 J. Ferreira Duarte, A. Assis Rosa \& T. Seruya (eds.)

John Benjamins Publishing Co., Amsterdam, 2006, 207 págs.

\section{Carlos Collantes Fraile}

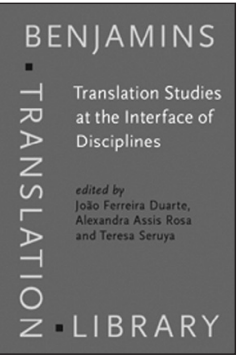

La obra Translation Studies at the Interface of Disciplines nos ofrece una amplia visión de los estudios de traducción desde una perspectiva interdisciplinar, gracias a la diversidad de temas y las diferentes especialidades que se tratan en esta monografía. Los editores, João Ferreira Duarte, Alexandra Assis Rosa y Teresa Seruya, han creado un compendio de artículos coherente y útil que presenta una panorámica del momento actual en los estudios de traducción, gracias a la cual resulta muy fácil hacerse una idea de los avances que se están produciendo en la disciplina y sentar las bases para un posible desarrollo posterior en la investigación en traducción e interpretación.

En las 207 páginas de este volumen, cuyo origen reside en el congreso "Translation (Studies): A Crossroad of Disciplines» celebrado en la Universidad de Lisboa en 2002, se aporta un retrato crítico sobre el estado actual de la rama de los Estudios de Traducción y su impacto en toda la traductología. En toda la obra se destaca la interdisciplinaridad patente en este movimiento: con la introducción de la cultura como elemento de traducción, sobreviene asimismo una insaciable sed de conocimiento especializado en la disciplina pues, al teorizar sobre la traducción en determinados ámbitos de especialidad, el investigador se encuentra con la innegable necesidad de extrapolar las bases teóricas de dichos dominios. En los Estudios de Traducción, estos variados enfoques se entremezclan con la teoría de la traducción para conseguir, en primer lugar, presentar una descripción de los sucesos que acaecen en el proceso traductor; en segundo lugar, facilitar una metodología para este cometido $y$, en tercer y último lugar, dar una respuesta posterior a las especificidades en el plano teórico y práctico de la traducción de cada tipo de texto. De ahí que, en la misma introducción del libro, los editores nos insten a afirmar que la traducción necesita claramente la colaboración de otras disciplinas, entre las que citan: la lingüística, el análisis del discurso, la pragmática, la sociolingüística, la sociología, los estudios culturales, etc.

La voluntad de afianzar y fundamentar esta (inter)disciplina, unida al ímpetu de contribuir al desarrollo de la teoría de la traducción, es lo que ha movido a João Ferreira Duarte, Alexandra Assis Rosa y Teresa Seruya a sumergirse en la coordinación y realización de este volumen. En dicho empeño, los editores abren su publicación con una prudente pero brillante introducción en la que presentan un extraordinario recorrido por los estudios de traducción, destacando la interdisciplinaridad de la que ya hemos hablado e incluso resaltando la necesidad de llevarla más allá por parte de este movimiento traductológico, de forma que nuestra rama pueda convertirse en un flujo constante de conocimiento entre unas y otras esferas del saber y, de este modo, ser objeto de un constante examen crítico interno que la propulse hacia el futuro.

A esta aclaratoria introducción, «Translation Studies at the Interface of Disciplines», le siguen tres partes claramente diferenciadas:

La primera parte titulada «New Perspectives on the Disciplinary Space of Translation» reco- 
ge una serie de participaciones que nos deleitan con un controvertido debate sobre los tipos y grados de la interdisciplinaridad dentro de los estudios de traducción y sobre la manera en que este hecho afecta a la realidad actual de dicha disciplina. En esta parte es necesario resaltar las destacadas aportaciones de teóricos de la traducción de la talla de Andrew Chesterman, Yves Gambier, Gideon Toury o Ma Rosario Martín Ruano. Los dos primeros nos ofrecen una revisión de sus propias tesis desde un punto de vista autocrítico sumamente constructivo, amparándose en otra rama de conocimiento como es la sociología. Por otro lado, Toury nos brinda una innovadora redefinición del concepto de texto y textualidad y el comportamiento traductor. Por último, Ma Rosario Martín Ruano aporta un recordatorio de la necesidad de adoptar una posición más crítica aún hacia las premisas fundamentales de los Estudios de Traducción.

La segunda parte titulada «Theoretical Models at Work» busca generar una reflexión acerca del papel que asumen las diferentes corrientes que se introducen y aplican a la teoría de la traducción y cómo éstas nos ayudan a avanzar en nuestra práctica con metodologías y conceptos. De este modo y gracias a los enfoques teóricos, se pretende mostrar también las nuevas posibilidades que aparecen a la hora de enunciar y suscitar nuevos movimientos traductológicos.

Por último, la tercera parte titulada «Texts and Contexts in Translation» enriquece la publicación mediante una gran variedad de artículos basados en ejemplos que nos ayudan a hacernos una idea de las traducciones que se llevan a cabo en diferentes géneros e idiomas, como por ejemplo portugués, chino, holandés o francés. Este último tramo del libro persigue un análisis exhaustivo del contexto tanto de originales como de traducciones que estén en continuo contacto con otras materias, como la teoría literaria, la historia, la cultura o el análisis del discurso.

El volumen en su totalidad nos presenta una revisión crítica de las teorías actuales de la traducción, es decir, podemos ver cómo enfoques que ya han asumido la interdisciplinaridad de nuestra rama del saber van desarrollándose y actualizándose con el paso del tiempo; algo que resulta de vital importancia a la hora de avanzar en cualquier campo.

Como conclusión, hay que añadir que los editores, João Ferreira Duarte, Alexandra Assis Rosa y Teresa Seruya, han conseguido recoger y componer una rica monografía de artículos que expone claramente las inquietudes actuales relacionadas con los estudios de traducción y que lo convierte en un volumen de obligada lectura para todo aquel que quiera sumergirse y profundizar más en la teoría actual de la traducción.

\section{Second Finding. A poetics of translation}

Barbara Folkart

University of Ottawa Press, Ottawa, 2007, 562 págs.

Miguel Ángel Montezanti

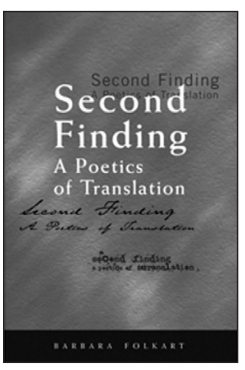
El libro de Barbara Folkart moverá a repensar la traducción a partir de la crítica que realiza sobre dicotomías que juzga poco fundamentadas, principalmente la célebre «domesticating» - «foreignizing». Promete ocuparse de traducciones reales que le permitan ilustrar el contraste entre lo que llama «writerly» y «non writerly». Hacen a esta densidad terminológica otros tec- 
nicismos tales como «faber» (Pound y Eliot), «lettre»y «traduction littérale»(Berman), «ratio difficilis» (Eco), «bénéfice du locuteur» 250 (Foucault). La buena praxis del traductor es la de aquél que hace como (no lo que) hizo el autor en L. O. Rechaza las traducciones miméticas que impiden el placer que nace de la poesía. Los poemas son esencialmente performativos. La «valencia» es la medida de esa performatividad. Una traducción que atienda exclusivamente a la denotación no podrá cumplir con la performatividad. Todo poema es un acto de «ratio difficilis», es decir, extranjerizante. Postula una nueva teoría, «writerly, non-replicative» que se enfoque menos sobre el texto o sobre las dimensiones sociológicas o ideológicas y sí más sobre el acto mismo de escribir; es decir, una poética de la traducción. No sin causticidad establece que desde el punto de vista de la teoría de la traducción la intertextualidad es «lo ya-dicho de lo ya-dicho». Lo que cuenta no es la arqueología de la intertextualidad sino el modo como el material intertextual opera en el poema, es decir, su valencia. Una traducción mimética engendrará en TL una réplica del poema de SL. Una concepción que apunte a lo que denomina «unidad de traducción» verá el poema como totalidad y no como suma de micro estructuras. La traducción «un-writerly» se caracteriza por la entropía y el desparramamiento. Para Folkart los poetas ingieren a otros poetas por medio de la traducción con el fin de «in-corporárselos». Zukofsky, uno de los ejemplos de Venuti, traduciría homofónicamente a Catulo como preparación para sus 80 Flowers. Algo semejante haría Eliot al traducir la Anabase de Saint John-Perse. La verdadera apropiación comienza con un acto de visualización capaz de imponer las palabras propias. Es su traducción provisoria de Anabase, Folkart reconoce que incurre en capitulaciones del tipo «palabra por palabra» por imposibilidad de aprehender partes de TO*. Pero el acento está puesto sobre el proceso de TT* y no sobre ST*. $\mathrm{Su}$ conclusión es sincera y demoledora: «Neither Eliot nor I have really succeeded in appropriating this canto, let alone deriving English poetry form it» (p. 257).

En el capítulo VII, «Visibility and Viability», la autora cuestiona acremente la noción de visibilidad, a la cual, igual que a la de fidelidad, moteja de pre-científica, ideologema borroso y poco investigado. La visibilidad es esencial, no accidental. Folkart relee cuidadosamente a Berman: su concepto de «traduction littérale» corresponde a una traducción que intenta recrear la «letra» del original, es decir su «textness» (¿textura?). Esto poco tiene que ver con la traducción «grainly foreignizing», que se detiene en las microestructuras. En su concepto, «visibilidad» es en la actualidad menos el producto de las estrategias estéticas que un vector de la ideología. L. Venuti, quien dice seguir a Berman, no lo sigue en verdad. Caracterizan la audacia y la profundidad al segundo; la simpleza y el empobrecimiento al primero. La preocupación de Venuti es ideológica, la de Berman, estética. La «traducción literal» de Berman revela la extrañeza intrínseca del original, su «inauguralidad».

Otro de los puntos que ataca es la «corrección» feminista de textos «machistas» por medio de la traducción. Opina que ésta es una forma de empobrecer un texto complejo reduciéndolo a una univocidad ideológica. La visibilidad, por ende, es vista como un teologema que tiñe a la traducción de grandiosidad ideológica en lugar de concentrarse sobre lo empírico ( $\mathrm{p}$. 333). La visibilidad de una traducción no confiere automáticamente autoría auténtica: «The translator is by definition celui qui vient après». Sólo el «faber» es dueño de verdad.

Camino a las paradojas, las traducciones que llama «grainy» o «minimalistas» son las más 
distorsionadoras: "Poet-centred,' for me, refers to the way the poem constructs its own point of origin». No se trata, entonces, de ningún «expressive I» ni de «unified subjectivity» (p.40o).

En el capítulo final, "Poetry as knowing", Folkart asegura que la poesía se refiere al conocer. La caracterización de la poesía según un enfoque sobre los tropos le resulta trivial por cuanto se contenta con el inventario post factum. Sólo la escritura es inaugural. Se equivocan los críticos que no sólo consideran que la traducción debe replicar a TO sino que ella misma debe ser vista como réplica.

Uno de los aspectos destacables de este trabajo es que Folkart practica la poesía, y si por momentos tenemos la sensación de un fastidio intolerante (poco «académico») en su crítica, no cabe duda de que su voz resulta legitimada por su praxis poética, lo que confiere a quien ejerce la crítica una compenetración que rara vez se halla en el crítico "profesional».

Otro, es la variedad de autores y de lenguas que aporta como ejemplos: el francés, el alemán, el latín, el italiano, el español; autores procedentes de distintas épocas y tradiciones culturales: Pierre Leyris, Milo de Angelis, Ovidio, Marianne Moore, Quevedo, Joyce, Dante, Saint John- Perse, etc.

Naturalmente, un libro de semejante densidad y espectro corre riesgos: uno de ellos sospecho que inevitable - es el de la subjetividad: ¿cómo distinguir la operación del «faber» o la traducción «writerly» de la otra, de la mera réplica? ¿No se deja Folkart guiar a veces por su impresionismo? Pero como justificación debe decirse que su trabajo concienzudo abre nuevos territorios de discusión y exploración. Y por el lado de quien reseña, cabe lamentar el no tener ni el inglés ni el francés como primeras lenguas para poder aprobar o rebatir a Folkart en su propio terreno.

\section{Os labirintos da tradução: a legendagem no cinema e a construção do imaginário} Sabine Gorovitz 78 págs.

Xosé Manuel Dasilva

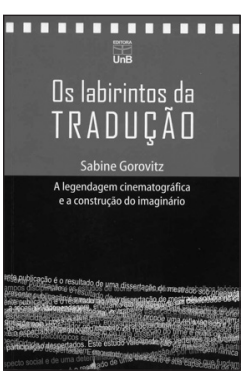
volumen, que apareció publicado en la colección Comunicação, coordinada por Dione Oliveira Moura e integrada en los servicios editoriales de la Universidad de Brasilia. Su autora es Sabine Gorovitz, docente de esta misma institución universitaria, quien posee una formación claramente interdisciplinar, ya que es graduada en Lenguas Extranjeras Aplicadas a la Economía y especialista en Dirección Audiovisual.

Sabine Gorovitz había publicado hasta ahora diferentes estudios de menor formato, como "Tradução e psicanálise», "Cinema e estética da recepção»y «Tradução e metamorfose». Este libro es una obra de superior fuste, y en su base se halla el trabajo académico de investigación A legendagem e a participação do espectador na construção da mensagem cinematográfica, dirigido por Denilson Lopes, cuya defensa tuvo lugar en la Facultad de Comunicación de la Universidad de Brasilia en el año 2000.

La idea primigenia de este libro, por lo que se advierte en la correspondiente introducción, surgió del propósito de vincular dos áreas de 
estudio no muy alejadas en determinados casos: la traducción y el cine. El objetivo esencial consistía en llevar a cabo una aproximación fructífera al fenómeno de interacción que se da entre el mensaje cinematográfico, cuando es recibido por medio de una versión subtitulada, y el espectador, a fin de percibir de qué forma la información contenida en los subtítulos es aprehendida en el momento de contemplar del producto.

De acuerdo con ello, en el análisis que realiza Sabine Gorovitz se aprecia la confluencia de tres vectores principales. E1 primero es la observación de los procesos de naturaleza mental que intervienen en la construcción del mensaje cinematográfico, especialmente los componentes psicológicos que se encuentran en la trastienda de este fenómeno. El segundo se cifra en el acercamiento a esta práctica comunicativa desde una perspectiva social, atendiendo de manera específica al contexto en el que se desarrolla. El último vector se relaciona con la tipicidad del subtitulado en calidad de acto de traducción en sí, calibrando su repercusión en lo que atañe a la recepción del mensaje.

Para la autora, la hipótesis de partida fundamental es que el espectador, cuando se sitúa ante una obra subtitulada, dispone de un margen de participación superior al que tiene si se trata de una obra doblada. La subtitulación, por evidentes razones de índole técnica, depara de modo inevitable como consecuencia un texto en el cual se pierde una porción nada despreciable del mensaje en comparación con el original. Además, se hace preciso tener en cuenta que el subtitulado implica necesariamente una labor de transvase desde el ámbito de la lengua oral al de la lengua escrita. Más aún, este transvase se sujeta a la obligación de circunscribirse a un espacio que es restringido en considerable grado sin remedio posible, lo que impone la utilización de un discurso de extensión mucho más parca.

Efectivamente, la circunstancia descrita es la causa de que el acceso al mensaje por parte del nuevo receptor se vea interferido por elementos externos al producto cinematográfico propiamente dicho, en buena medida ajenos al acto de creación que se produjo en su momento. En opinión de Sabine Gorovitz, tal interferencia tiene como resultado un doble movimiento de pérdidas y de ganancias. Por un lado, el espectador se ve condenado a experimentar vacíos en el proceso de percepción. Por otro lado, el espectador tiene ante sí, sin embargo, la opción de completar esos vacíos con su subjetividad, participando activamente en la configuración del sentido final que haya que dar al mensaje cinematográfico.

Con el objeto de ahondar minuciosamente en la hipótesis de partida que acabamos de exponer, el volumen aparece estructurado en tres apartados, además de contar con un capítulo introductorio y otro conclusivo. En el primero se trasladan a la esfera del arte de la cinematografía algunos de los fundamentos de la conocida corriente, en el dominio literario, denominada Estética de la recepción. El segundo se centra preferentemente en el análisis de los ingredientes que conforman la dimensión cultural que encierra el hecho cinematográfico. E1 tercer apartado, por último, con el título "Cinema e tradução: a questão do tradutor», constituye la parte ciertamente más sustancial del estudio, y está dedicada a examinar la repercusión de la subtitulación en lo que es el proceso de intelección, por parte del receptor, de cada película.

Al hilo de la publicación de esta monografía, debe ponerse de relieve que la subtitulación representa una actividad bastante arraigada en el mundo lusófono, primordialmente en Brasily 
Portugal. En concreto en este último país (aunque cada vez el doblaje resulte menos infrecuente, sobre todo en lo que respecta a determinadas entregas televisivas) todavía es predominante el uso de subtítulos en la traducción de productos importados. En otros tiempos más que afortunadamente ahora, la subtitulación supuso hasta cierto punto un elemento discriminatorio en lo que concierne a aquellas capas de la población con dificultades manifiestas para la lectura, convirtiéndose de tal manera en una barrera infranqueable. Algunas veces se ha dicho que el éxito desde hace décadas de las telenovelas brasileñas entre los portugueses, de magnífica factura en su mayoría dicho sea de paso, tuvo bastante que ver con la posibilidad que permitían de que fuesen contempladas por todos los sectores de la población, incluso por aquellos menos letrados, los cuales podían acompañar su emisión sin el obstáculo de la subtitulación.

Antes de poner fin a nuestro comentario, nos gustaría señalar la falta de justicia que se observa muchas veces en la poca estima que reciben las contribuciones brasileñas a los estudios de traducción debido casi siempre a su procedencia periférica o, como diría el brillante traductor y traductólogo Haroldo de Campos, a su condición ex-céntrica. En esta ocasión hemos prestado atención a este libro de Sabine Gorovitz, pero no queremos dejar pasar la oportunidad de citar al menos otras aportaciones surgidas en Brasil durante los últimos años. En lo que no aspira a ser más que una relación de urgencia, mencionemos entre otros los siguientes volúmenes: Tradução de humor. Transcriando piadas (2002), de Marta Rosas; À margem das traduçôes (2003), de Agenor Soares de Moura; Traduzir com autonomia. Estratégias para o tradutor em formação (2003), de Fábio Alves, Célia Magalhães y Adriana Pagano; Notas do tradutor e processo tradutório. Análise e reflexão sob uma pers- pectiva discursiva (2003), de Solange Mittmann; Tradução e adaptação. Encruzilhadas da textualidade em "Alice no País das Maravilhas", de Lewis Carrol, e «Kim», de Rudyard Kipling (2005), de Lauro Maia Amorim; Competência em tradução. Cognição e discurso (2005), de los referidos Fábio Alves, Célia Magalhães y Adriana Pagano; y A tradução como um outro original. "Como é» de Samuel Beckett (2006), de Ana Helena Souza. De fecha mucho más reciente indiquemos estos títulos: Dizer o «mesmo» a outros. Ensaios sobre tradução (2008), de Adail Sobral; y Teoria e prática da tradução (2008), de Juliana Cristina Faggion Bergmann y Maria Fernanda Lisboa. No creemos, ni mucho menos, que este constante manantial bibliográfico brasileño vaya a reducir su caudal en los próximos años.

\section{La traduction audiovisuelle. Approche interdisciplinaire du sous-titrage}

Jean-Marc Lavaur \& Adriana Serban Collection Traducto, De Boeck, Bruselas, 2008, I64 págs.

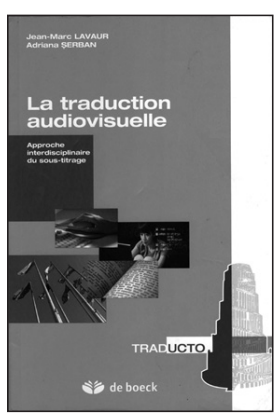

Isabel Cómitre Narváez La obra que presentamos es el volumen cuarto de la colección Traducto, manuales especializados destinados a estudiantes y docentes de traducción e interpretación, dirigida por el profesor Mathieu Guidère de l'eti (École de Traduction et d'Interprétation) de la Universidad de Ginebra y director del gRETI (Groupe de Recherche en Traduction et Interprétation). 
Este volumen aborda el subtitulado como modalidad de traducción audiovisual y recoge una selección de las ponencias presentadas en las Jornadas Internacionales sobre subtitulación celebradas en la Universidad de Montpellier 3, en junio de 2006. El hecho de que el libro aparezca en lengua francesa es significativo e indica el resurgimiento del interés por la subtitulación en países tradicionalmente «dobladores» como Francia, España, Alemania, Austria e Italia frente a países con tradición para la subtitulación como Grecia, Portugal o los países nórdicos. Por ello, la presente obra constituye una interesante aportación a esta modalidad de traducción audiovisual (TAV) por su carácter innovador e interdisciplinar. En efecto, los autores son todos eminentes especialistas de esta modalidad de TAV que proceden de disciplinas distintas y, a su vez, complementarias: la traductología, el cine, la lingüística y la psicología cognitiva.

Los editores de la obra y coordinadores de las Jornadas Internacionales, Jean-Marc Lavaur y Adriana Serban, abren este volumen que se compone de nueve capítulos en torno a dos ejes fundamentales: un primer eje centrado en la historia del subtitulado y un segundo eje centrado en la profesión, la docencia e investigación. La obra tiene una orientación pedagógica ya que incluye al final de cada capítulo dos apartados "Allez plus loin» y «Testez vos connaissances» con una bibliografía específica y preguntas sobre el tema tratado.

En el primer capítulo, Jean-François Cornu, doctor en doblaje y subtitulado cinematográfico y traductor profesional, presenta un trabajo titulado "Pratiques du sous-titrage en France des années I930 à nos jours». Se trata de una perspectiva histórica del subtitulado en Francia desde los años 30 hasta la actualidad. El autor expone detalladamente los motivos de la aparición de los primeros subtítulos en las pantallas de cine y la evolución de éstos. Asimismo, describe el empirismo inicial de los primeros subtituladores hasta las técnicas más actuales que se apoyan en el lenguaje cinematográfico, en las investigaciones sobre percepción y audición así como en el tratamiento de la información. Finalmente, denuncia la situación actual de las empresas de subtitulación y edición de DVDs, generalmente motivadas por intereses económicos y comerciales, que influyen negativamente en la calidad de las traducciones.

En esa misma línea de aproximación histórica, Christian Viviani, docente e investigador de la Universidad de París I, La Sorbona, nos ofrece en el capítulo segundo «Le sous-titrage dans le cinéma américain: de la plaisanterie à la nécessité dramatique», una visión crítica del cine norteamericano desde los albores del cine mudo hasta la actualidad. Tradicionalmente, debido a la hegemonía de la lengua inglesa, en la edad de oro de Hollywood, sólo un זо\% de las películas eran subtituladas, proyectadas en salas de arte y ensayo (art houses) y calificadas de foreign cinema. La presencia de directores europeos en Hollywood que lucharon por el respeto de la identidad lingüística y el uso de subtítulos en las versiones originales fue decisiva. El autor analiza numerosos ejemplos de películas desde $M r$. Wu de W. Night (1927), pasando por Manbunt de F. Lang (I94I) hasta El Padrino de F. Coppola con diálogos y subtítulos en italiano o La Pasión de M. Gibson con subtítulos en arameo.

La aportación de Jorge Díaz Cintas, docente e investigador sobre teoría y práctica de la subtitulación y uno de los grandes expertos en el tema, inicia las contribuciones 
dedicadas a la enseñanza y aprendizaje del subtitulado. En el capítulo tercero titulado «Pour une classification du sous-titrage à l'époque du numérique», el autor propone una definición del subtitulado que le permite situar esta forma de traducción, íntimamente relacionada con la tecnología, frente a otras modalidades de traducción audiovisual como el doblaje, el voice-over o voces superpuestas, la interpretación simultánea, la narración, el doblaje parcial, el comentario libre, la traducción a la vista, la subtitulación para sordos y la audiodescripción. Explora otras modalidades recientes como la subtitulación para teatro y ópera o los fansubs y ofrece una tipología de los subtítulos basada en parámetros lingüísticos, técnicos, métodos de proyección y formatos de distribución.

El capítulo cuarto corre a cargo de Joselia Neves de la Universidad de Coimbra (Portugal) y está dedicado a la subtitulación para sordos. En este artículo titulado «Le sous-titrage pour sourds et malentendants: à la recherche d'une qualité possible», la profesora portuguesa insiste en el lugar que ocupa actualmente este tipo de subtitulación en el panorama audiovisual y en su creciente auge debido a la televisión digital e Internet. Presenta propuestas prácticas para la mejora y la armonización de las normas a nivel europeo que tengan en cuenta las necesidades reales del público receptor. Estas propuestas consideran, entre otros, la importancia de los factores técnicos relacionados con los métodos de transcripción y con los modos de presentación de los subtítulos para poder establecer unas normas aceptables en cada lengua y cultura receptora. Todo ello con vistas a una mejora cualitativa del subtitulado intralingüístico en todas sus formas.

Coordinadora de varios proyectos sobre accesibilidad en los medios y formación de traductores en la Universidad Autónoma de Barcelona, Pilar Orero, en el capítulo quinto «Le format des sous-titres: les mille et une possibilités» propone una taxonomía basada en el formato de los subtítulos, factor fundamental en la recepción de los textos traducidos. Orero ofrece una serie de parámetros relacionados con la tipografía de los subtítulos como el tipo de caracteres, la dimensión, los colores, el contraste, el fondo de proyección, el número de caracteres, de líneas y el espacio que ocupan los subtítulos en la pantalla así como el cambio de secuencias, etc. Todos estos parámetros se establecen a partir de la velocidad de lectura de los espectadores y deben, obviamente, mantener una sincronía con la imagen y los diálogos originales.

Basándose en su dilatada experiencia profesional en la subtitulación de documentales para cine, televisión y radio, Francine Kaufmann, docente en la Universidad de Bar-Ilan (Israel), describe en el capítulo sexto «Le sous-titrage des documentaires: défis et enjeux de l'établissement du texte de départ», las distintas etapas de realización de un documental así como los modos de traducción más frecuentes de este género dramático, entre otros, el subtitulado y el voice-over o voces superpuestas. La autora of rece un interesante estudio de caso en hebreo y en francés en el que fue necesaria la «reconstrucción» arbitraria del texto de partida lo que le permite cuestionar el papel y los límites del traductor en este ámbito.

Adriana Serban, coeditora de la obra, coorganizadora de las Jornadas y del máster de traducción audiovisual de la Universidad de Montpellier 3, aborda los problemas lingüísticos y culturales de los subtítulos y plantea la dicotomía traducción/adaptación en el capí- 
tulo séptimo, «Les aspects linguistiques du sous-titrage». La autora analiza numerosos extractos de guiones de películas francesas y norteamericanas que plantean distintos problemas de traducción (lingüísticos y culturales). A continuación, propone unas estrategias globales de transferencia lingüística y cultural de los subtítulos. Naturalización, normalización y simplificación constituyen algunas de las estrategias de transferencia más frecuentes en el estudio llevado a cabo por la profesora Serban.

Por su parte, Zoë Pettit, docente en la Universidad de Greenwich (Reino-Unido), se centra en la dimensión semiótica de los subtítulos en el capítulo octavo, «Le soustitrage: le rôle de l'image dans la traduction d'un texte multimodal». La autora insiste en la complejidad del mensaje audiovisual y la interacción entre los distintos códigos verbales, icónicos, sonoros y cinéticos, por ejemplo, la situación de los personajes en el espacio, los gestos y movimientos de los personajes, el tono de voz, la entonación, códigos que están marcados culturalmente. El subtitulador deberá tener en cuenta las relaciones de interdependencia que mantienen todos estos códigos entre sí para una adecuada transposición a otra lengua. A partir de ejemplos de series televisivas, Pettit demuestra que la lectura de los subtítulos es un proceso cognitivo adicional que se superpone a la percepción y a la comprensión de todos estos códigos.

Finalmente, la obra se cierra con el capítulo noveno a cargo del doctor y profesor en psicología cognitiva Jean-Marc Lavaur de la Universidad de Montpellier «La compréhension des films sous-titrés» que presenta tres estudios empírico-descriptivos realizados en laboratorio sobre grupos de estudiantes francófonos y anglófonos. Los estudios pretenden arrojar luz sobre los procesos cognitivos que los espectadores desarrollan durante el visionado de una película en lengua extranjera. El objetivo de dichos estudios es evaluar el efecto de los subtítulos sobre la comprensión y la memorización del mensaje fílmico. Los resultados de los estudios muestran que los subtítulos tienen un impacto productivo sobre la comprensión y la memorización y, por consiguiente, favorecen el aprendizaje de las lenguas extranjeras.

En definitiva, podemos afirmar que se trata de una obra muy interesante que aborda la subtitulación como modalidad de traducción audiovisual desde múltiples perspectivas. Podemos mencionar, quizás, la referencia constante al género dramático (películas, documentales, etc.) y echar en falta el análisis de otros géneros susceptibles de ser subtitulados, algunos de fuerte empuje como, por ejemplo, el género publicitario (anuncios, spots corporativos, etc) o el género de entretenimiento (videojuegos, play-station, etc.). No obstante, esta obra constituye una herramienta muy útil para estudiantes, docentes e investigadores no sólo por la reflexión teórica y la perspectiva multidisciplinar que of rece sino también porque aporta una visión de conjunto para la formación de los futuros traductores audiovisuales y la práctica profesional de la traducción para el subtitulado en relación con otras modalidades y ámbitos del conocimiento. 
Prozessorientiertes

Qualitätsmanagement im

Dienstleistungsbereich Übersetzen.

Leipziger Studien zur angewandten

Linguistik und Translatologie. Hrg. Peter A Schmitt. Bd. 2.

Elvira Mertin

Peter Lang, Fráncfort, 2006, 472 págs..

María José Varela

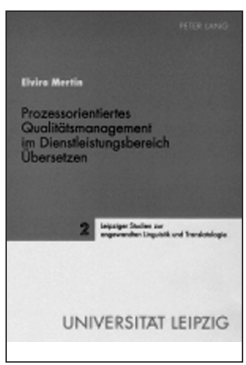

E1 presente tomo versa sobre el control de calidad en la traducción, entendiendo esta como perteneciente al sector económico de servicios. Entre los temas incluidos cabe destacar el desarrollo de las bases traductológicas del control de calidad, el comentario de las diferentes normas y normativas relacionadas así como los criterios de evaluación de la traducción como producto y como proceso, respectivamente.

La gestión de calidad se conoce en la industria desde mediados de los años cincuenta; al trasladarse este concepto al sector servicios, también ha encontrado aplicación en el campo de la traducción. Pero aquí, ¿qué significa? La nueva norma europea de calidad para servicios de traducción EN-I5038 existe ya de modo oficial desde el año 2006. Sin embargo, hay que reconocer que, por su vaguedad, poco aporta en criterios concretos al traductor para que él o su empresa mejoren el proceso de traducción. Incluso bitácoras como Algo más que traducir de Pablo Muñoz Sánchez con aportaciones del estilo de «Traducciones y control de calidad» se muestran más cercanas a la realidad del traductor.
Esta monografía de Elvira Mertin critica precisamente la falta de relación entre la teoría sobre la gestión de la calidad en traducción y la práctica profesional. Partiendo del marco legislativo y de las normas existentes, pasa a describir las condiciones previas para adaptar convenientemente el proceso y, en consecuencia, el producto de la traducción para que se ajuste al concepto de servicio. E1 análisis que realiza tiene en cuenta las teorías traductológicas que, según la autora, exigen un cambio epistemológico para interpretar el proceso traductor como sistema abierto, pues se encuentra en situación de constante influencia recíproca con los subprocesos que lo conforman, a la vez que con otros procesos que los abarcan. Una de las propuestas para la mejora de la calidad se basa precisamente en la interconexión de los diferentes procesos de traducción.

El control de calidad conlleva una evaluación del producto «traducción». La autora presenta diferentes modelos traductológicos y didácticos de evaluación sugeridos por diversos autores y que incluyen criterios para ponderar los errores de traducción. Asimismo toma en consideración las normas DIN 2345, EN-I5O38 y SAE J245O, esta última válida exclusivamente en el sector de la automoción, antes de pasar a describir los criterios empleados en el IBM Translation Center, el Servicio de Traducción de la UE, en tekom (Sociedad para la comunicación y la documentación técnicas), Siemens y SAP Language Services. Finalmente analiza con mayor detenimiento y como estudio de caso el método y la plantilla de evaluación que emplea la DaimlerChrysler AG para las traducciones, evaluación que incluso propone calificaciones como equivalencias de la valoración global. 
El capítulo 5 es, en nuestra opinión, el de mayor importancia, pues en él la autora explica en profundidad el proceso de análisis y desarrollo de un proyecto de traducción en una empresa que incluye un serio control de calidad, tomando como ejemplo las traducciones que se realizan en DaimlerChrysler.

En resumen, este trabajo refleja las nuevas tendencias en gestión de calidad para la traducción, que incluyen un cambio de perspectiva: un desplazamiento del enfoque desde la evaluación a la producción de calidad.

El presente estudio nos muestra, pues, una visión del desarrollo más actual del control de calidad de la traducción, tal y como se lleva a cabo en empresas de excelencia; y también nos ofrece pautas de cómo formar a los futuros traductores preparados a afrontar los retos del denominado «total quality management».

\section{Translation as Intervention \\ Jeremy Munday (ED.) \\ Continuum, Londres/Nueva York, 2007, 165 págs.}

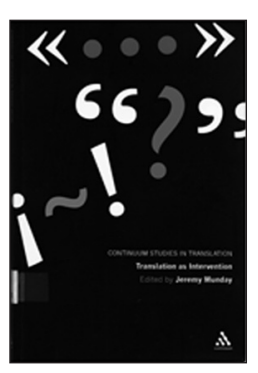

Francisca García Luque

E1 hilo conductor de los capítulos que componen esta obra colectiva es la concepción de la traducción como un fenómeno comunicativo complejo al que no son ajenos factores sociales, políticos e ideológicos. Las reflexiones sobre la actividad traductora e investigadora provenientes de ámbitos muy dispares ilustran sobre las implicaciones de traducir y sobre el modo en que esta actividad supone siempre una intervención en el proceso comunicativo del que forma parte y una alteración de aquello que se está traduciendo y con ello, a veces, incluso de la realidad.

E1 primer ejemplo de ello lo proporciona Carol Maier, quien se centra en la necesidad de conocer mejor las implicaciones individuales y colectivas de la traducción como profesión. Esta autora defiende que los traductores cumplen una función social, que es interpretada por ellos mismos y por la sociedad bajo un prisma determinado. Maier señala la conveniencia de saber cómo se percibe que el traductor, en calidad de profesional de la comunicación, interviene socialmente y cómo esto tiene, a su vez, un impacto emocional y físico en él. Esta misma idea de la intervención del traductor en el texto la retoma en el segundo capítulo Brian Mossop, defendiendo que esa intervención se produce a través de la elección de una voz o estilo de redacción, que puede ser neutralizador, distanciador o imitador. E1 autor establece una jerarquía entre estas voces, con la neutralizadora en primera posición, y defiende que el traductor elige conscientemente cuál de las tres posibilidades va a emplear en función del contexto social y político en el que se ha de mover.

Concentrándose en la intervención que puede suponer la traducción en los planos social e ideológico, los capítulos tercero y cuarto abordan dos contextos geográficamente alejados y que constituyen un ejemplo de la transformación que la traducción como actividad puede acarrear. E1 tercero, correspondiente a Rita Kothari, pone su atención en el estudio de cómo detrás de las traducciones al inglés de la literatura escrita en dalit, una lengua minoritaria de una casta inferior de la India, se esconde un activismo 
político que lucha contra la injusticia de una sociedad fragmentada artificialmente. Así, el inglés, que antaño fue la lengua opresora del Imperio, mediante una política de traducción comprometida se convierte en vehículo de reconocimiento y transformación. En el cuarto capítulo, Liu Yameng reclama atención sobre la traducción y la investigación que se realizan lejos de los focos de pensamiento tradicionales. Por un lado, exhibe una actitud crítica ante los cánones traductológicos occidentales. Por otro, cuestiona las estrategias extranjerizantes adoptadas por Occidente para traducir textos de otras áreas geográficas, al tiempo que defiende la idea que ella denomina justicia representacional, una forma de conseguir que la traducción sirva para acercar las culturas mediante el conocimiento mutuo y el respeto.

Los siguientes capítulos retoman la idea de la intervención del traductor sobre el texto a través de distintos mecanismos. Así, Jef Verschueren se centra en que todo acto de comunicación supone una negociación de significados y un proceso de exégesis y adaptación permanente a los nuevos contextos que emanan del desarrollo del acto comunicativo. El traductor también interviene en la elección de significados y mediante ésta modela el proceso de comunicación. Basil Hatim, por su parte, nos habla de la dificultad de traducir lenguas culturalmente lejanas en las que los rasgos orales de los textos escritos exigen una intervención del traductor mediante un análisis detenido del texto, del discurso subyacente y del género al que pertenece para elegir la estrategia de traducción que mejor reproduzca la intención comunicativa del original.

Los capítulos séptimo y octavo analizan el contexto laboral de los traductores e intér- pretes y las influencias recíprocas entre estas dos instancias: profesionales y entorno sociolaboral. En el primero de ellos, Rosemary M. H. Moeketsi describe la situación de los intérpretes judiciales en Suráfrica y la necesidad de unas competencias que van más allá de lo lingüístico y de lo jurídico para poder cumplir su cometido. En el segundo, Joanna Drugan nos ilustra sobre cómo el acceso a herramientas de TA y TAO y la actitud de los traductores fue crucial en la adaptación de los servicios de traducción de la UE al aumento del volumen de trabajo que se produjo en 2004.

Para cerrar la obra, Francesca Billiani vuelve a la idea de la traducción como intervención, esta vez en el plano social o artístico, examinando cómo dos editoriales italianas (Mondadori y Einaudi) seleccionaron determinado tipo de textos poéticos extranjeros para ser traducidos en la Italia de la posguerra, con el fin de crear un nuevo canon literario más proclive a nuevos valores de izquierda y romper así con la visión estética y elitista de la poesía que había imperado en la época fascista.

El principal valor de estos nueve trabajos reside en superar visiones un tanto simplistas de la traducción y en explicar que esta actividad supone una doble intervención. En primer lugar, en el plano individual, implica posicionarse frente al texto que se está traduciendo; en segundo lugar, en el plano colectivo, supone hacer llegar ideas o realidades a otra cultura, elementos todos ellos susceptibles de intervenir y modificar tanto la cultura de llegada como sus relaciones con la cultura de partida. 


\section{Diálogos intertextuales: Pocahontas}

260 Veljka Ruzicka Kenfel (ed.)

Peter Lang, Francfort, 2008, I32 págs.

Juan Jesús Zaro

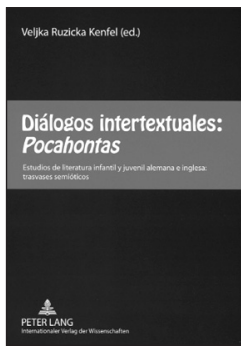

Este libro es uno de los frutos del proyecto de investigación Transformación funcional de la literatura infantil y juvenil en la sociedad multimedia. Aplicación de un modelo teórico de crítica a las adaptaciones audiovisuales en español de las obras infantiles inglesas y alemanas que lleva a cabo el grupo de investigación «Literatura infantil y juvenil y su traducción» en la Universidad de Vigo.

El proyecto, en el que convergen líneas de investigación de los ámbitos filológico y traductológico, tiene dos objetivos principales: uno, contribuir a la mejora cualitativa de los productos audiovisuales infantiles y juveniles vertidos al español; el otro, donde se inserta este libro, analizar los libros infantiles que surgen a partir de productos audiovisuales concretos, en este caso la película Pocahontas, un producto de la factoría Disney estrenado en 1995. El libro es, por tanto, una obra compacta: todos sus capítulos - escritos, en este orden, por las profesoras Celia Vázquez García, Carmen Becerra Suárez, Lourdes Lorenzo García y Ana Pereira Rodríguez-, versan sobre los distintos productos artísticos, en este caso libros y texto fílmico, surgidos a partir de la publicación de la novela de David Garnett Pocahontas (1933).

Pocahontas or the Nonparell of Virginia es un relato, supuestamente histórico, que narra la historia de la niña nativa americana que salvó al capitán inglés John Smith de ser ejecutado a manos de sus captores indígenas. Garnett, cuya obra más conocida es la novela Aspects of Love (1955), que en los años ochenta se convertiría en un musical obra de Andrew Lloyd Weber, fue un escritor inglés ligado al círculo de Bloomsbury, que exhibe en su producción literaria las mismas contradicciones que muchos de sus componentes quienes, a pesar de desarrollar actitudes radicalmente progresistas en lo social y experimentales en lo artístico, dejan entrever una postura etnocéntrica, hoy trasnochada. Celia Vázquez, autora del primer capítulo, vislumbra también esa postura en la película de Disney, cuya representación de Pocahontas considera «una de las más perversas distorsiones imaginables de la historia colonial norteamericana» (p. 44). La distancia ideológica entre novela y película, a pesar de la ranciedad de la historia de Garnett, es evidente, y la película, un producto más de la factoría Disney, anclado en normas y valores del más puro tinte conservador.

En el capítulo segundo, Carmen Becerra analiza minuciosamente el texto fílmico. Primero, su relación con la novela de Garnett -que fue, por cierto, traducida al español por Luis Jordá y publicada en I943; echamos de menos alguna referencia más a este texto traducido-, y luego sus características argumentales: el final abierto, las relaciones de género, la visión conservadora y capitalista que subyace y la mínima, aunque explícita, crítica al fenómeno de la colonización incluida en la película. Para Becerra, la versión fílmica de Pocahontas es también una distorsión al haber convertido una historia colonial en un «cuento de hadas».

Lourdes Lorenzo es la autora del capítulo tercero, dedicado al estudio del doblaje al español peninsular de la película de Disney. La 
película, una traducción intersemiótica en términos de Jakobson, es para esta investigadora, «un producto independiente, aunque con evidentes deudas a las fuentes literarias» (p. IO2). Y el doblaje al español que en su día se encargó a Joanna Stier, un trabajo de calidad que mantiene la ilusión del texto original: Pocahontas se expresa en inglés (doblado al español), lengua que desconoce y que hablan solo los invasores de sus tierras, con perfecta naturalidad. El texto traducido para el doblaje mantiene también, como característica general, un rasgo de naturalidad que pretende ser aceptable en la cultura meta y que, según Lorenzo (p. 92), «es la norma tanto en la teoría como en la práctica de la traducción contemporánea». Tras el análisis pormenorizado de la dimensión lingüística y cultural del doblaje de la película, se defiende su calidad, considerando las expectativas del público al que va dirigida, mayoritariamente infantil, y las restricciones inherentes a la traducción audiovisual. A diferencia de las investigadoras anteriores, Lorenzo sí defiende la Pocahontas de Disney, un producto fílmico del que «se derivan más beneficios que perjuicios del primer contacto de los niños con la historia-mito de Pocahontas» (p. I03).

Finalmente, Ana Pereira estudia, en el capítulo cuarto, la traducción al español de los textos derivados de la película, en concreto el libro derivado directamente de ella, cuyo original y su correspondiente traducción española se editaron en 1995 en Estados Unidos y España sin que aparezca, en el caso de la versión española, el nombre del traductor (o traductores). Pereira demuestra, por medio de un pertinente análisis, la falta de calidad de la traducción anónima española, que redunda en aspectos como la simplificación del texto traducido con respecto al original o la falta de sincronía entre texto e ilustraciones.
En suma, un libro interesante tanto por la naturaleza de la investigación realizada - el análisis de un producto artístico y sus derivaciones-, como por el planteamiento - se trata del mismo producto y sus sucesivas traducciones intersemióticas-, lo que, insistimos, confiere a la obra una coherencia poco habitual en este tipo de monografías y la convierte en modelo a tener en cuenta en investigaciones similares. Interesante también la variedad de posiciones ideológicas de las autoras ante los productos investigados, probablemente inevitable en una obra colectiva como ésta. El resultado final es que la obra no se queda en un frío e insustancial análisis descriptivo, algo que hay que agradecer muy especialmente..

\section{La evaluación en los estudios de Traducción e Interpretación} María-José Varela Salinas (ed.) Bienza, Sevilla, 2006, 330 págs.

Ana Isabel García Esteban

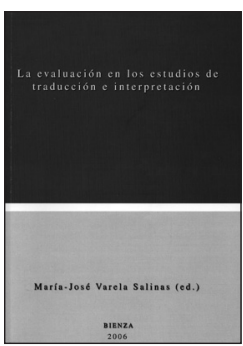

Esta obra está constituida por un total de i5 colaboraciones en las que se ponen de manifiesto las últimas tendencias en didáctica de la traducción y la interpretación, prestando especial atención al proceso de evaluación. Los objetivos fundamentales de los que se parte son, por un lado, la sistematización de los criterios de evaluación para los estudios de traducción e interpretación y, por otro, la descripción del papel fundamental de la evaluación y la autoevalua- 
ción en la adquisición de la competencia traductora e interpretativa por parte de los alumnos. Para ello, se lleva a cabo un análisis de las 262 principales dificultades que se presentan a la hora de evaluar los conocimientos adquiridos por los estudiantes y se proponen soluciones en función de tales dificultades.

El volumen está dividido en dos secciones: la primera cuenta con diez contribuciones y se centra en la evaluación de la traducción, mientras que la segunda, con cinco contribuciones, está dedicada a la evaluación de la interpretación. A continuación, indicaremos de manera resumida la temática principal de cada una de ellas según su orden de aparición en la obra.

Al comienzo de la primera sección nos encontramos con dos capítulos en los que se estudian los errores de traducción y se presentan algunas de sus clasificaciones. En el primer capítulo, a cargo de Guadalupe Ruiz Yepes, se hace un recorrido por las principales corrientes traductológicas y se da cuenta de cómo estas han influido en la didáctica de la traducción y en los métodos evaluativos, además de indicar qué se entiende por «error de traducción» desde cada una de ellas. Asimismo, la autora llama la atención sobre la necesidad de buscar un enfoque integrador que permita sacar provecho de todas estas corrientes. A continuación, Christiane Nord, partiendo de una concepción funcionalista, define el concepto de «error de traducción» y lo clasifica en función de una serie de problemas de traducción identificados. Basándose en esta clasificación, la autora propone un modelo sistematizado de evaluación.

Las dos contribuciones que siguen ahondan sobre los distintos tipos de evaluación y destacan la importancia de cada uno de ellos en el proceso de enseñanza-aprendizaje de la tra- ducción. Mariana Orozco Jutorán profundiza en la evaluación formadora, diagnóstica, formativa y sumativa, y da cuenta de cómo hacer uso de cada una de ellas para sacar el máximo partido a las clases de traducción y contribuir a que el alumno se corresponsabilice de su formación. Por su parte, Heike van Lawick y Ulrike Oster manifiestan la importancia de las llamadas competencias transversales — tales como el dominio de las nuevas tecnologías, el aprendizaje autónomo y la capacidad de análisis y de síntesis, entre otras - para el aprendizaje de la traducción. Asimismo destacan la relevancia de la evaluación formativa, la evaluación mutua y la autoevaluación en relación con tales competencias.

A continuación, Àngel Tortadès, defiende la relevancia de la interacción colaborativa - en el sentido de interacción social - para la adquisición de la competencia traductora por parte de los alumnos. Desde esta perspectiva socioconstructivista de la didáctica de la traducción el autor considera que no sólo debe evaluarse el producto final, sino que es necesario asimismo prestar atención al proceso de aprendizaje que ha seguido el alumno.

En el siguiente capítulo, María-José Varela Salinas (editora de este libro) y Encarnación Postigo Pinazo destacan la importancia que posee el orientar la enseñanza de la traducción e interpretación hacia las exigencias del mercado laboral. Tras analizar cuáles son actualmente tales exigencias, las autoras proponen un modelo de enseñanza-aprendizaje en el que juega un papel relevante la evaluación. Asimismo, destacan la necesidad de que los alumnos adquieran subcompetencias fundamentales hoy día en el mundo profesional de la traducción, tales como el manejo de las nuevas tecnologías de la información y de la comunicación. 
No podía faltar en esta obra un capítulo destinado a la evaluación de las habilidades del alumno para documentarse correctamente, por la importancia que esta tarea posee tanto para el traductor como para el intérprete. Así, Rocío Palomares Perraut y Carmen Camarero Gómez presentan un modelo de evaluación para determinar si el alumno de Traducción e Interpretación ha adquirido las competencias documentales que se le exigen en la asignatura Documentación Aplicada a la Traducción.

A continuación, siguen tres capítulos dedicados a la evaluación de la traducción con la implicación de lenguas concretas. E1 primero de ellos, de Nicolás Roser Nebot, profundiza en la lengua árabe y destaca la importancia del desarrollo de la capacidad autoevaluativa del alumno en el proceso de enseñanza-aprendizaje de la traducción del y al árabe. Por su parte, María del Carmen Balbuena Torezano, basándose en su experiencia docente en un máster de traducción, presenta un modelo evaluativo para traducciones de textos periodísticos alemanes hacia el español y que es aplicable a alumnos que poseen el alemán como lengua materna. La autora ofrece asimismo ejemplos de diversos parámetros de evaluación tanto lingüísticos como extralingüísticos. Posteriormente, María-José Varela Salinas reflexiona sobre los conceptos de evaluación y autoevaluación e investiga sobre su evolución a lo largo del tiempo. A continuación, nos ofrece un inventario de errores cometidos en los últimos años por los alumnos de cuarto curso de Traducción e Interpretación de la Universidad de Málaga al llevar a cabo traducciones especializadas inversas (español-alemán). Junto a dichos errores, la autora ofrece posibles soluciones para corregirlos y destaca la importancia que tiene en este proceso la autoevaluación, entendida esta como la toma de conciencia por parte del alumno de sus fallos y la reflexión sobre estos.

La segunda sección de la obra está constituida por un total de cinco contribuciones centradas en la evaluación de la interpretación. Abre esta segunda sección Ángela Collados Aís con un capítulo en el que manifiesta la necesidad de que el mundo profesional se refleje en la forma de evaluar las interpretaciones de los alumnos en el ámbito académico. Tras revisar brevemente los trabajos existentes en materia de calidad de la interpretación, la autora lleva a cabo un estudio empírico en el que trata de determinar cuáles son las expectativas tanto de los usuarios como de los intérpretes profesionales con respecto a una interpretación. Tras el estudio, extrae conclusiones de interés que deberán ser tenidas en cuenta a la hora de evaluar a los alumnos.

A continuación, se presentan dos capítulos que tratan aspectos poco estudiados en el ámbito de la interpretación. En primer lugar, Emilia Iglesias Fernández investiga sobre la agradabilidad de la voz del intérprete. Para ello, la autora realiza un estudio empírico con el fin de determinar qué entienden los usuarios de las interpretaciones por voz agradable, y extrae conclusiones que deberán ser tenidas en cuenta en la evaluación de los alumnos de interpretación. Por su parte, Esperanza Macarena Pradas Macías investiga acerca de la existencia de un patrón pausístico en la interpretación simultánea. Como en el caso anterior, esta autora lleva a cabo un estudio empírico y extrae conclusiones interesantes aplicables a la práctica y a la didáctica de este tipo de interpretación.

Debido al interés que existe actualmente por los estudios empíricos en torno a la interpretación, Jessica Pérez-Luzardo Díaz investiga si la figura del asesor y corrector interjuez podría contribuir a aumentar el grado de objetividad 
de tales estudios en relación con el diseño y la valoración de los resultados obtenidos.

Cierra el volumen un capítulo de Encarnación 264 Postigo Pinazo en el que, tras analizar el estado de la cuestión en cuanto a la investigación en técnicas y modalidades de interpretación, la autora plantea cuáles son los principales problemas que acontecen en la docencia de la interpretación. Asimismo, propone posibles soluciones a tales problemas y destaca la importancia de la autoevaluación para fomentar el aprendizaje del alumno.

Tras todo lo comentado anteriormente se deduce que nos encontramos ante una obra de gran utilidad para la docencia, ya que se recogen las últimas tendencias en la enseñanza de la traducción y la interpretación, en las que el mundo profesional está muy presente. Esto resulta de gran interés para el ámbito académico si tenemos en cuenta la importancia que tiene el instruir a los estudiantes para que sean capaces de enfrentarse con éxito al mercado laboral. De ahí la necesidad de adaptar los estudios universitarios a las exigencias de dicho mercado, con el fin de formar profesio- nales cualificados capaces de afrontar los retos laborales que se les presenten.

Todas las reflexiones que aparecen en el libro están basadas en criterios pedagógicos actuales, de corte constructivista, en los que la evaluación es concebida como parte del proceso de enseñanza-aprendizaje de la traducción e interpretación, y en los que prima la necesidad de que el alumno se corresponsabilice de su formación y participe activamente en ella. De esta manera se deja a un lado la concepción tradicional del proceso evaluativo, de corte conductista, según la cual la evaluación se concibe como la puntuación obtenida exclusivamente en una prueba final. Asimismo, en los contenidos del libro se encuentran muy presentes los objetivos del nuevo Espacio Europeo de Educación Superior, lo que indica que está en consonancia con la nueva legislación en materia de educación universitaria.

Todos estos factores contribuyen a que el presente volumen sea una obra de elección para la actualización de conocimientos en materia de docencia en traducción e interpretación. 